\title{
Reduksi Waste dan Peningkatan Kualitas pada Proses Produksi Brownies Kukus Cokelat dengan Menggunakan Metode Lean Six Sigma
}

\author{
Salsabila Aulia Nurfaidah* \\ Prodi Teknik Industri, Fakultas Teknik, Universitas Islam Bandung, \\ Indonesia. \\ *salsabilauliaa@gmail.com
}

\begin{abstract}
CV. X is a company engaged in the food industry. One of the products produced is steamed chocolate brownies. High consumer demand for these products causes companies to have to produce in large quantities so that demand can be met. However, the company always produces defective products in large quantities, which is about $2.13 \%$ of the production and there is also waste that causes the production flow to be inefficient to the maximum. Therefore, the lean six sigma method is used as an effort to reduce waste and improve quality. SIPOC diagram, current state value stream mapping and 7 waste questionnaire were conducted to identify waste. It was found that the dominant types of waste that occur are defects, transportation and waiting. Process Cycle Efficiency (PCE) is used to measure the efficiency level based on the comparison of the processing time and production lead time values from the VSM mapping, the PCE current state value is 57.14\%. DPMO and Sigma Level are used to measure the company's sigma capability. The resulting average sigma level value in April June 2021 is 2.84 . Waste problems in CV.X are caused by human, material, machine, method and environmental factors. Efforts were made to improve the efficiency and level of company sigma. Recommendations for improvement are carried out by providing training to operators, increasing work supervision, making work standardization visually, scheduling machine maintenance, increasing the number of trolleys, adding dough boxes equipped with filters, designing visual controls for work in process reports, redesigning production layouts (Re-layout), as well as applying kaizen blitz.
\end{abstract}

Keywords: Lean Six Sigma, Waste, Process Cycle Efficiency, Sigma Level.

Abstrak. CV. X merupakan salah satu perusahaan yang bergerak pada bidang industri pangan. Salah satu produk yang dihasilkan adalah brownies kukus cokelat. Permintaan konsumen yang tinggi terhadap produk tersebut menyebabkan perusahaan harus memproduksi dalam jumlah yang besar agar permintaan dapat terpenuhi. Namun perusahaan selalu menghasilkan produk cacat dalam jumlah banyak yaitu sekitar 2,13\% dari hasil produksi dan juga terdapat waste yang menyebabkan aliran produksi tidak efisien secara maksimal. Oleh karena itu, metode lean six sigma digunakan sebagai upaya untuk mereduksi waste dan meningkatkan kualitas. Diagram SIPOC, value stream mapping current state dan kuesioner 7 waste dilakukan untuk mengidentifikasi waste. Ditemukan bahwa jenis waste yang dominan terjadi yaitu defect, transportasi dan menunggu. Process Cycle Efficiency (PCE) digunakan dalam mengukur tingkat efisiensi berdasarkan perbandingan nilai processing time dan production lead time hasil pemetaan VSM, diperoleh nilai PCE current state sebesar 57,14\%. DPMO dan Level Sigma digunakan untuk mengukur kapabilitas sigma perusahaan. Dihasilkan rata-rata nilai level sigma pada bulan April - Juni 2021 adalah 2,84. Permasalahan waste di CV.X disebabkan oleh faktor manusia, material, mesin, metode dan lingkungan. Dilakukan upaya perbaikan untuk dapat meningkatkan efisiensi dan level sigma perusahaan. Rekomendasi perbaikan dilakukan dengan memberikan pelatihan kepada operator, peningkatan pengawasan kerja, membuat standarisasi kerja secara visual, melakukan penjadwalan perawatan mesin, penambahan jumlah trolley, penambahan box adonan yang dilengkapi saringan, perancangan visual control untuk report work in process, perancangan ulang layout produksi (Re-layout), serta menerapkan kaizen blitz.

Kata Kunci: Lean Six Sigma, Waste, Process Cycle Efficiency, Level Sigma. 


\section{A. Pendahuluan}

CV. X adalah perusahaan yang memproduksi berbagai macam jenis produk kue brownies dan pastry. Salah satu produk yang dihasilkan adalah brownies kukus cokelat. Kepopuleran produk brownies kukus cokelat yang dihasilkan oleh CV. X menyebabkan permintaan yang cukup tinggi sehingga perusahaan melakukan produksi dalam jumlah yang besar setiap harinya agar permintaan konsumen dapat terpenuhi. Kecepatan produksi dan kualitas hasil produk harus mampu dimiliki oleh perusahaan agar dapat menjaga loyalitas konsumen.

Berdasarkan wawancara dan pengamatan yang telah dilakukan di pabrik CV. X, ditemukan bahwa pada produksi brownies kukus cokelat sering dihasilkan produk cacat dan proses yang tidak efisien karena terjadi beberapa aktivitas pemborosan. Produk cacat yang dihasilkan menyebabkan kuantitas produksi harian tidak dapat terpenuhi. Selain daripada itu, timbulnya pemborosan pada proses produksi pun dapat berdampak pada lead time produksi, semakin banyak pemborosan yang terjadi pada lantai produksi maka lead time akan semakin besar dan mengakibatkan perusahaan semakin lama dalam memenuhi permintaan konsumen.

Disajikan data jumlah produksi, jumlah produk defect, rework dan reject serta persentase dari masing-masing jumlah defect, rework, dan reject dari produk brownies kukus cokelat yang dihasilkan CV. X pada bulan April - Juni 2021 yang dapat dilihat pada tabel 1.

Tabel 1. Data Jumlah Produksi dan Produk Defect pada Bulan April - Juni 2021

\begin{tabular}{|c|c|c|c|c|c|c|c|}
\hline Bulan & $\begin{array}{c}\text { Jumlah } \\
\text { Produksi } \\
\text { (Unit) }\end{array}$ & $\begin{array}{c}\text { Jumlah } \\
\text { Produk } \\
\text { Defect (Unit) }\end{array}$ & $\begin{array}{c}\text { Persentase } \\
\text { Defect }\end{array}$ & $\begin{array}{c}\text { Jumlah } \\
\text { Rework } \\
\text { (Unit) }\end{array}$ & $\begin{array}{c}\text { Persentase } \\
\text { Rework }\end{array}$ & $\begin{array}{c}\text { Jumlah } \\
\text { Reject } \\
\text { (Unit) }\end{array}$ & $\begin{array}{c}\text { Persentase } \\
\text { Reject }\end{array}$ \\
\hline April & 263.764 & 5.479 & $2,08 \%$ & 4.583 & $1,74 \%$ & 896 & $0,34 \%$ \\
\hline Mei & 418.596 & 11.042 & $2,64 \%$ & 9.245 & $2,21 \%$ & 1.797 & $0,43 \%$ \\
\hline Juni & 277.407 & 6.278 & $2,26 \%$ & 5.122 & $1,85 \%$ & 1.156 & $0,42 \%$ \\
\hline
\end{tabular}

Sumber: Divisi Quality Control CV. X (2021)

Terkait dengan permasalahan yang terjadi, penelitian dilakukan agar dapat memberikan usulan perbaikan bagi perusahaan dalam mengatasi permasalahan mengenai produk cacat dan aktivitas pemborosan lain. Permasalahan tersebut harus segera diatasi agar kinerja dari perusahaan tidak menurun dalam memenuhi permintaan konsumen serta perusahaan tetap dapat menjaga loyalitas konsumen. Permasalahan yang terjadi dapat diatasi dengan melakukan penerapan metode lean six sigma pada kegiatan produksi di CV. X.

Berdasarkan latar belakang yang telah diuraikan, maka dapat ditentukan rumusan masalah dan tujuan penelitian sebagai berikut:

Rumusan masalah:

1. Apa jenis pemborosan yang terjadi dan akar penyebab dari pemborosan yang ditemukan pada proses produksi brownies kukus cokelat?

2. Berapa tingkat efisiensi dan level sigma perusahaan dalam memproduksi brownies kukus cokelat?

3. Bagaimana usulan perbaikan yang dapat dilakukan oleh perusahaan untuk dapat mengurangi pemborosan dan meningkatkan kualitas pada produksi brownies kukus cokelat?

4. Bagaimana dampak dari perbaikan yang dilakukan terhadap nilai efisiensi dan level sigma perusahaan?

Tujuan penelitian:

1. Mengidentifikasi jenis-jenis pemborosan dan faktor yang mempengaruhi pemborosan yang saat ini muncul pada proses produksi brownies kukus cokelat.

2. Mengidentifikasi tingkat efisiensi dan level sigma perusahaan dalam memproduksi produk brownies kukus cokelat.

3. Merancang usulan perbaikan pada kegiatan produksi di perusahaan agar dapat memenuhi tujuan perusahaan.

4. Mengidentifikasi dampak dari perancangan perbaikan terhadap nilai efisiensi dan level sigma perusahaan. 


\section{B. Metodologi Penelitian}

Penelitian ini bertujuan untuk dapat mereduksi waste dan meningkatkan kualitas pada proses produksi brownies kukus cokelat di CV. X. Hal tersebut dapat dicapai dengan menggunakan metode lean six sigma. Lean six sigma merupakan sebuah konsep perbaikan dengan mengkombinasi metode lean dengan six sigma. Lean merupakan konsep pemikiran guna memperoleh customer value secara tinggi dengan penggunaan sumber daya yang rendah (1). Sedangkan Six sigma merupakan bagian dari metodologi Total Quality Management (TQM) yang dirancang agar dapat mereduksi biaya dan meningkatkan kualitas yang bertujuan untuk mengeliminasi beberapa proses dengan perbaikan berdasarkan perspektif kualitas pelanggan dan kinerja proses serta dampak dari perubahan proses (2). Sehingga dapat dikatakan bahwa Lean six sigma sebagai sebuah pendekatan untuk mengetahui serta mereduksi segala aktivitas yang tidak memberikan nilai tambah melalui peningkatan kinerja secara berkala untuk mendapatkan tingkat enam sigma (3).

Umumnya langkah penerapan lean six sigma sama seperti langkah pada fase six sigma yaitu Define, Measure, Analyze, Improve, dan Control (DMAIC) dan menerapkan beberapa tools yang biasa digunakan dalam Lean (4). Dengan demikian pada penelitian ini proses pengolahan data dilakukan dengan menggunakan langkah-langkah six sigma berupa DMAIC. Namun pada penelitian tahap yang dilakukan hanya sampai pada tahap Improve.

Data yang dibutuhkan dalam proses pengolahan data dikumpulkan melalui hasil wawancara dan observasi. Terdapat dua jenis data yang dikumpulkan yaitu data primer dan data sekunder. Data primer dikumpulkan melalui pengamatan secara langsung di perusahaan. Adapun beberapa data yang termasuk data primer yaitu data waktu aktivitas (Terdiri dari waktu proses operasi, waktu transportasi, waktu set up, waktu menunggu, waktu pemeriksaan, dan waktu proses rework), jumlah operator dari setiap proses, faktor penyesuaian dan faktor kelonggaran. Data sekunder diperoleh dari narasumber atau data yang sudah ada dari perusahaan, data sekunder yang dibutuhkan yaitu jumlah produksi, jumlah produk yang mengalami cacat (defect), jumlah rework, dan jumlah produk reject pada bulan Juli 2021.

Tahap Define, merupakan tahap identifikasi permasalahan yang dilakukan tools diagram SIPOC, pemetaan aliran produksi dengan pembuatan value stream map current state, dan Kuesioner 7 Waste untuk mengidentifikasi lebih lanjut mengenai waste yang terjadi selama proses produksi. Tahap Measure, merupakan tahapan pengukuran atas permasalahan yang telah teridentifikasi dilakukan dengan perhitungan nilai Process Cycle Efficiency (PCE), DPMO dan Level Sigma. Tahap Analyze, dilakukan analisis dan validasi terhadap akar penyebab dari permasalahan yang terjadi dilakukan dengan menggunakan tools diagram sebab akibat (fishbone diagram). Tahap Improve, merupakan proses untuk memberikan usulan perbaikan atas permasalahan untuk mencapai tujuan penelitian dilakukan dengan melakukan berbagai upaya perbaikan diantaranya yaitu dengan menerapkan tools lean manufacturing yaitu standard work dan visual display.

Tahapan akhir pada penelitian ini terdiri dari analisis yang dilakukan dengan pembuatan value stream map future state dan juga perhitungan PCE dan level sigma setelah adanya usulan perbaikan.dan kesimpulan.

\section{Hasil Penelitian dan Pembahasan Tahap Define}

Tahap identifikasi permasalahan diawali dengan pembuatan diagram SIPOC, kemudian pemetaan aliran produksi dengan Value Stream Mapping (VSM) serta identifikasi pemborosan dengan kuesioner 7 waste.

Diagram SIPOC dibuat untuk mengidentifikasi berbagai elemen yang relevan pada proses produksi dimulai dari supplier hingga dikirim sampai kepada customer. Adapun untuk diagram SIPOC pembuatan brownies kukus rasa cokelat di CV. X dapat dilihat pada Gambar 1. 


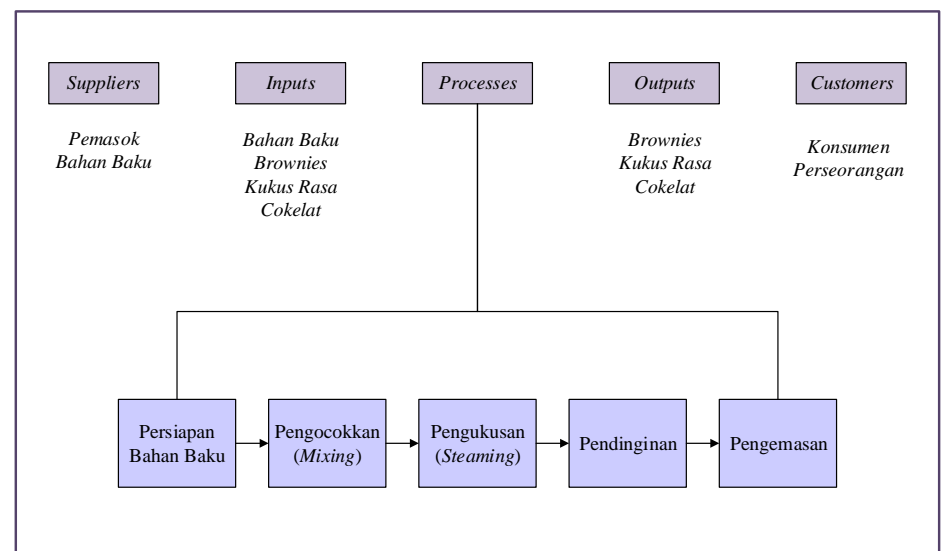

Gambar 1. Diagram SIPOC Pembuatan Brownies Kukus Cokelat di CV.X

Berdasarkan Gambar 1. menunjukkan berbagai elemen yang relevan pada proses produksi dimulai dari supplier hingga dikirim sampai kepada customer.

- Supplier untuk proses produksi brownies kukus rasa cokelat di CV.X terdiri dari supplier untuk berbagai jenis bahan baku produk. Selain itu terdapat vendor yang telah bekerja sama dengan CV. X untuk menyediakan kemasan dan juga vendor untuk loyang.

- Inputs yang dibutuhkan untuk memproduksi produk brownies kukus rasa cokelat berupa bahan baku yang terdiri dari tepung terigu, cokelat bubuk, air, susu kental manis, perisa, telur, minyak kelapa, garam, gula pasir, dan pengemulsi. Selain itu dibutuhkan pula input berupa bahan pendukung lain seperti kertas roti dan cairan pengoles loyang.

- Processes yang dilakukan untuk dapat menghasilkan produk brownies kukus rasa cokelat terdiri dari proses persiapan bahan baku dan loyang, pengocokan (mixing), pengukusan, pendinginan dan packaging.

- Output yang dihasilkan adalah produk brownies kukus rasa cokelat yang telah selesai dikemas dan siap untuk didistribusikan.

- Customer yang akan menikmati produk brownies kukus rasa cokelat merupakan konsumen perseorangan.

Value stream map current state dibuat untuk memetakan kondisi aliran material serta informasi yang saat ini terjadi selama proses produksi brownies kukus cokelat di CV. X. Adapun untuk VSM current state ditunjukkan pada Gambar 2.

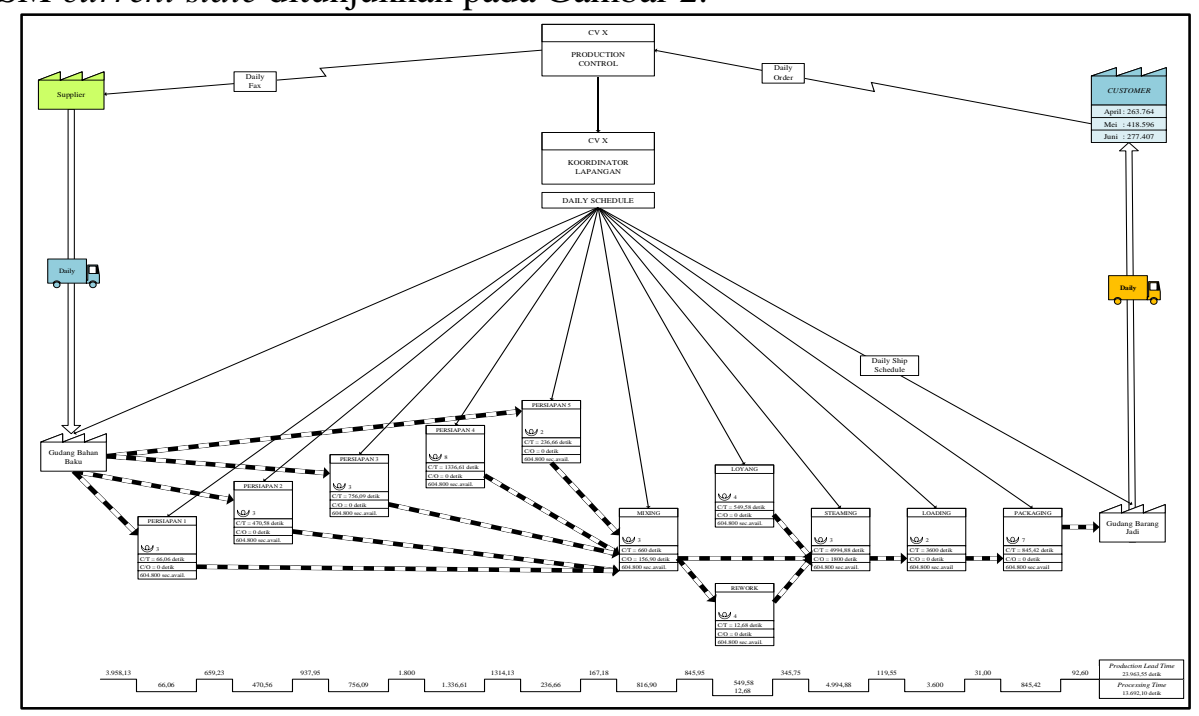

Gambar 2. Value Stream Map Current State 
Berdasarkan Gambar 2. diperoleh nilai processing time sebesar 13.692,10 detik dan total nilai total production lead time yaitu sebesar 23.963,55 detik.

Identifikasi waste dengan menggunakan kuesioner 7 waste dilakukan melalui dua tahap, yaitu pertama melakukan penyebaran kuesioner 7 waste terlebih dahulu lalu langkah selanjutnya melakukan pembobotan waste. Hasil pembobotan waste ditanmpilkan dalam bentuk grafik yang dapat dilihat pada Gambar 3.

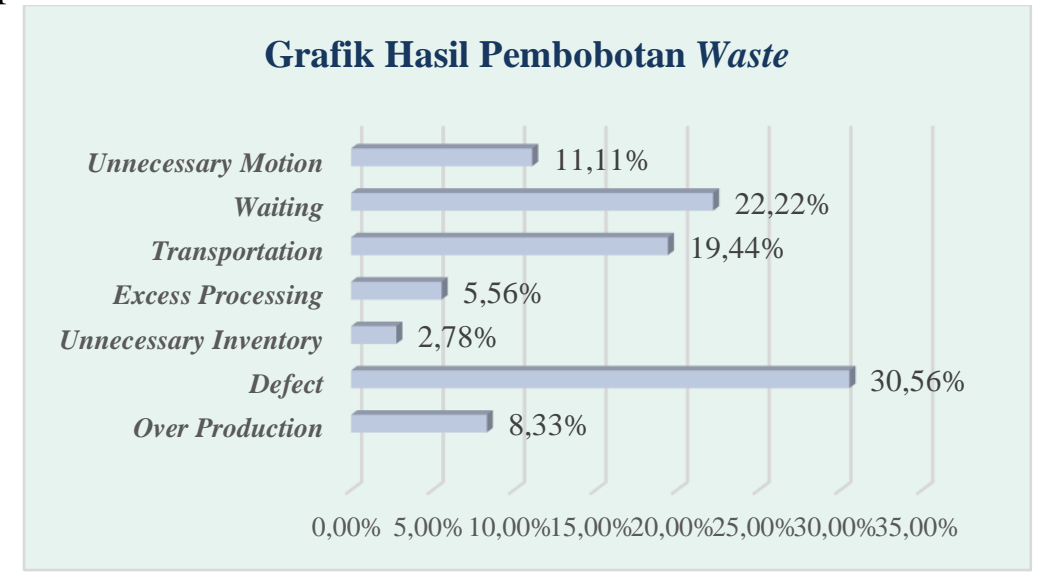

Gambar 3. Grafik Hasil Pembobotan Waste

\section{Tahap Measure}

Tahap pengukuran atas permasalahan yang telah teridentifikasi dilakukan melalui perhitungan Process Cycle Efficiency (PCE) untuk mengukur tingkat aktivitas yang tidak memberikan nilai tambah pada lantai produksi serta perhitungan DPMO dan level sigma untuk mengukur tingkat kapabilitas perusahaan.

Perhitungan nilai Process Cycle Efficiency (PCE) dilakukan dengan melakukan perbandingan antara nilai Value Added Time (VA) terhadap Total Lead Time (TLT).

Adapun untuk memperoleh nilai PCE pada kondisi perusahaan saat ini, dilakukan dengan perhitungan yang merujuk pada persamaan (II - 1) sebagai berikut:

$$
\begin{aligned}
& \text { Process Cycle Efficiency }(\mathrm{PCE})=\frac{\text { Value Added }(V A)}{\text { Total Lead Time }(\text { TLT })} \times 100 \% \\
& \text { Process Cycle Efficiency }(\mathrm{PCE})=\frac{13.692,10 \text { detik }}{23.963,55 \text { detik }} \times 100 \%=57,14 \%
\end{aligned}
$$

Berdasarkan hasil perhitungan PCE dengan nilai sebesar 57,14\%, maka peningkatan efisiensi masih memiliki peluang yang besar.

Perhitungan nilai sigma dilakukan untuk mengetahui kapabilitas perusahaan terhadap produk cacat yang dihasilkan. Rata-rata perhitungan nilai sigma pada bulan April - Juni 2021 dapat dilihat pada Tabel 2. Berdasarkan hasil nilai rata-rata sigma pada Tabel 2. dapat disimpulkan bahwa kapabilitas perusahaan masih harus ditingkatkan kembali untuk mencapai 6 sigma.

Tabel 2. Rata - rata DPMO dan Level Sigma Bulan April - Juni 2021

\begin{tabular}{|c|c|c|}
\hline Bulan & Rata - rata DPMO & Level Sigma \\
\hline April & 5404,74 & 2,78 \\
\hline Mei & 5041,68 & 2,81 \\
\hline Juni & 5536,12 & 2,77 \\
\hline \multicolumn{2}{|c|}{ Rata - rata } & $\mathbf{2 , 8 4}$ \\
\hline
\end{tabular}




\section{Tahap Analyze}

Tahap analyze mengacu pada hasil identifikasi pemborosan yang menghasilkan tiga pemborosan tertinggi yaitu defect, transportasi dan menunggu. Dilakukan analisis dengan menggunakan diagram sebab-akibat (diagram fishbone). Cacat (defect) pada produk brownies kukus cokelat dikategorikan dalam beberapa jenis cacat yaitu terdapat air di permukaan atas atau bawah produk, lepas, cekung, retak, belah, bantat dan basah. Pembuatan diagram fishbone dibuat terhadap jenis cacat tersebut yang dikelompokkan berdasarkan jenis cacat yang identik. Gambar 4. sampai dengan Gambar 6. menunjukan diagram sebab akibat untuk jenis waste defect yang telah dikelompokkan.

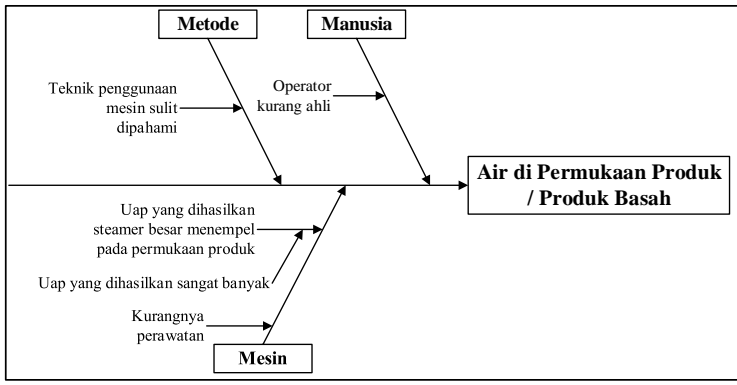

Gambar 4. Diagram Fishbone Jenis Defect Air Permukaan Produk dan Produk Basah

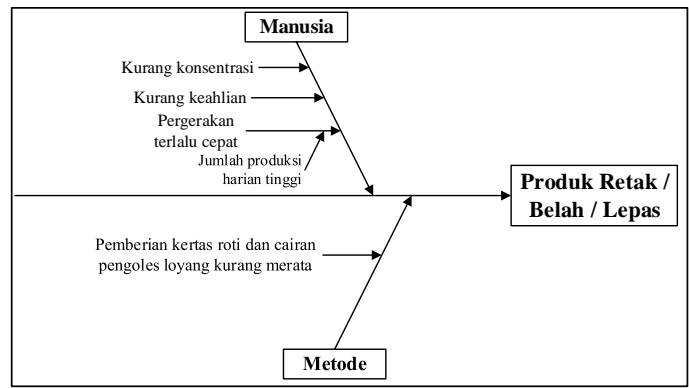

Gambar 5. Diagram Fishbone Jenis Defect Produk Retak, Belah dan Lepas

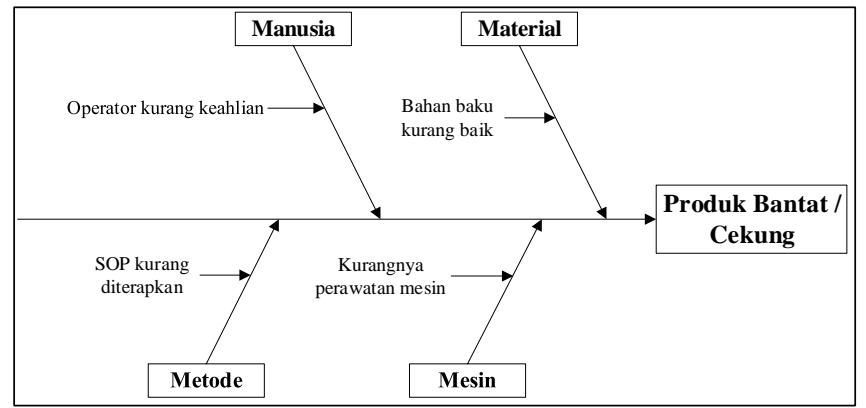

Gambar 6. Diagram Fishbone Jenis Defect Produk Bantat atau Produk Cekung

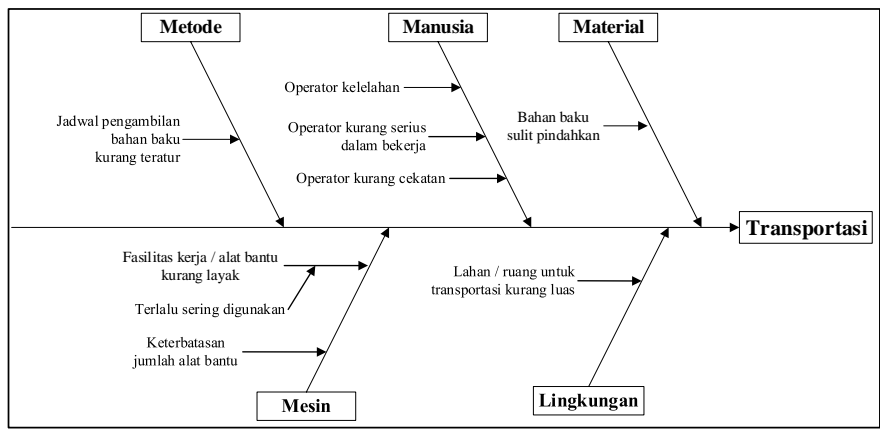

Gambar 7. Diagram Fishbone Waste Transportasi 


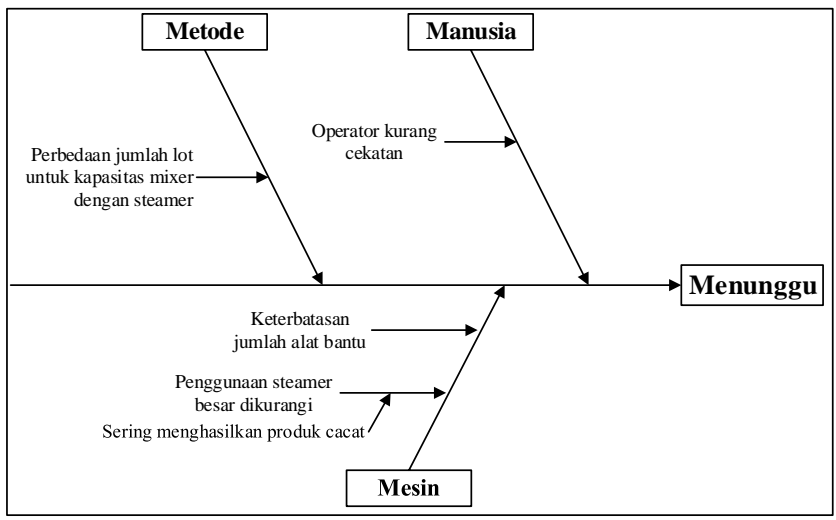

Gambar 8. Diagram Fishbone Waste Menunggu

\section{Tahap Improve}

Tahap improve dalam penelitian ini merupakan tahap pemberian usulan perbaikan berdasarkan permasalahan yang telah dilakukan identifikasi pada tahap define dan analisis akar penyebab pada tahap analyze. Usulan perbaikan yang direkomendasikan untuk mereduksi waste dan meningkatkan kualitas produk adalah dengan memberikan pelatihan kepada operator, peningkatan pengawasan kerja, membuat standarisasi kerja secara visual, melakukan penjadwalan perawatan mesin, penambahan jumlah trolley, penambahan box adonan yang dilengkapi saringan, perancangan visual control untuk report work in process, perancangan ulang layout produksi (Re-layout), serta menerapkan kaizen blitz.

\section{Value Stream Map Future State}

Pemetaan aliran produksi dengan value stream map future state dilakukan untuk kondisi setelah adanya beberapa upaya perbaikan. Berkaitan dengan hal tersebut, berbagai waktu yang digunakan dalam pemetaan kondisi yang akan datang merupakan waktu yang diperoleh berdasarkan asumsi apabila perusahaan mengimplementasikan rekomendasi perbaikan yang diberikan. Adapun untuk VSM future state ditunjukkan pada Gambar 9.

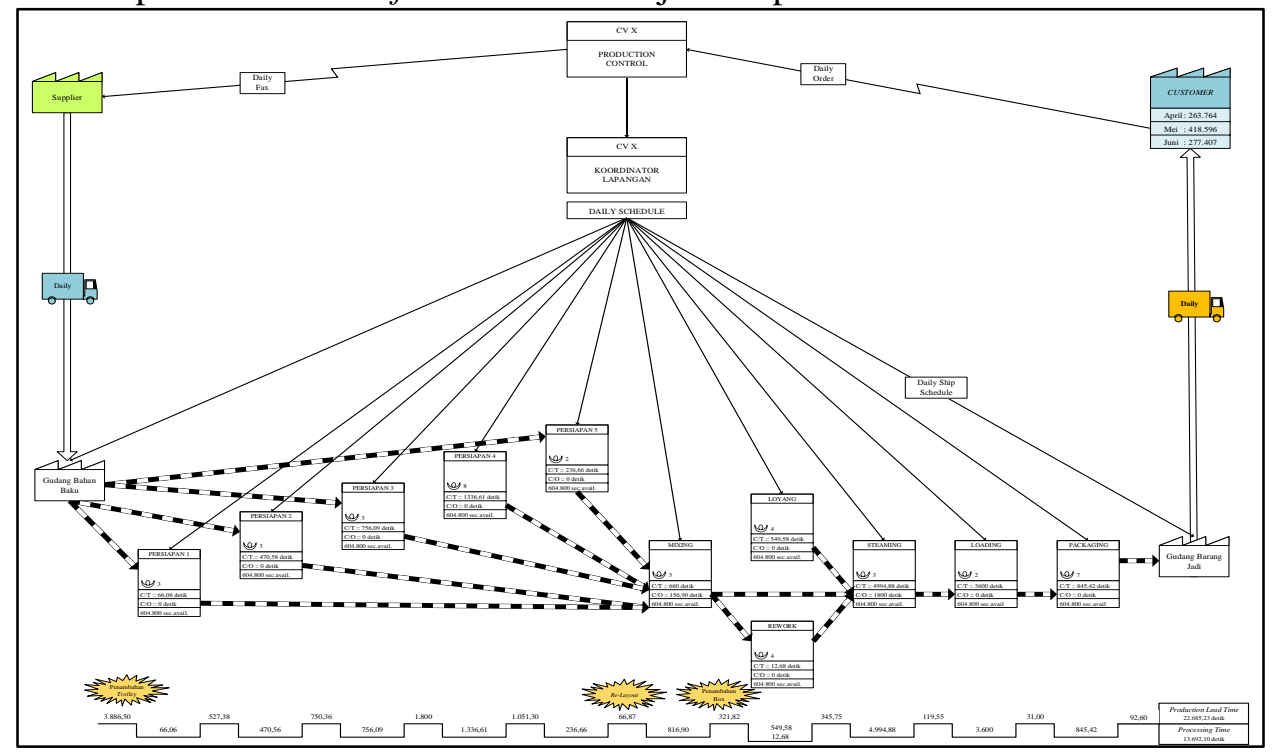

Gambar 9. Value Stream Map Future State

Berdasarkan Gambar 9. diperoleh nilai processing time sebesar 13.692,10 detik dan total nilai total production lead time yaitu sebesar 22.685,23 detik. Dilakukan perhitungan PCE future state dengan persamaan sebagai berikut:

$$
\text { Process Cycle Efficiency }(\mathrm{PCE})=\frac{\text { Value Added }(V A)}{\text { Total Lead Time }(T L T)} \times 100 \%
$$




$$
\text { Process Cycle Efficiency }(\mathrm{PCE})=\frac{13.692,10 \text { detik }}{22.685,23 \text { detik }} \times 100 \%=60,36 \%
$$

Hasil perhitungan menunjukkan bahwa nilai PCE future state yaitu sebesar 60,36\%. Terjadi peningkatan PCE sebesar 3,22\% sehingga dapat dikatakan bahwa tingkat efisiensi proses produksi meningkat.

\section{Perbaikan Level Sigma}

Usulan perbaikan yang diberikan diharapkan jumlah produk cacat berkurang sehingga level sigma dapat meningkat. Berdasarkan hasil diskusi dengan pihak perusahaan usulan perbaikan dapat dilakukan dengan ekspektasi pengurangan jumlah produk cacat adalah sebesar 30\%. Ratarata perhitungan nilai sigma pada bulan April - Juni 2021 setelah adanya perbaikan dapat dilihat pada Tabel 3.

Tabel 3. Rata - rata DPMO dan Level Sigma Bulan April - Juni 2021 Setelah Perbaikan

\begin{tabular}{|c|c|c|}
\hline Bulan & Rata - rata DPMO & Level Sigma \\
\hline April & $3.784,31$ & 2,92 \\
\hline Mei & $3.529,18$ & 3,00 \\
\hline Juni & $3.875,28$ & 2,93 \\
\hline \multicolumn{2}{|c|}{ Rata - rata Level Sigma } & $\mathbf{2 , 9 5}$ \\
\hline
\end{tabular}

\section{Kesimpulan}

Berdasarkan pembahasan dalam penelitian ini, peneliti menyimpulkan beberapa hasil penelitian sebagai berikut:

1. Hasil identifikasi waste menunjukkan bahwa terdapat 3 jenis waste yang dominan terjadi pada aliran produksi brownies kukus cokelat sehingga menyebabkan aliran produksi kurang efisien. Waste tersebut adalah defect, waiting dan transportasi.

2. Waste yang terjadi pada aliran produksi brownies kukus cokelat disebabkan oleh beberapa faktor yaitu faktor manusia, mesin, material, metode dan lingkungan.

3. Nilai sigma dipengaruhi oleh jumlah produksi, jumlah produk cacat serta Critical To Quality (CTQ). Pada penelitian ini produk cacat dipengaruhi oleh empat CTQ yaitu bahan baku, mesin, operator, dan proses. Dihasilkan nilai rata - rata level sigma pada bulan April - Juni 2021 adalah sebesar 2,84. Angka tersebut menandakan bahwa kapabilitas proses $\mathrm{CV}$. X masih jauh dari yang diinginkan.

4. Usulan perbaikan yang direkomendasikan untuk mereduksi waste dan meningkatkan kualitas produk adalah dengan memberikan pelatihan kepada operator, peningkatan pengawasan kerja, membuat standarisasi kerja secara visual, melakukan penjadwalan perawatan mesin, penambahan jumlah trolley, penambahan box adonan yang dilengkapi saringan, perancangan visual control untuk report work in process, perancangan ulang layout produksi (Re-layout), serta menerapkan kaizen blitz.

5. Asumsi apabila perbaikan telah diimplementasikan, terjadi perubahan pada nilai PCE dan level sigma. Pada kondisi current nilai PCE adalah sebesar 57,14\% sedangkan pada kondisi future sebesar $60,36 \%$. Adanya peningkatan nilai PCE menunjukkan bahwa tingkat efisiensi dari proses produksi brownies kukus cokelat meningkat. Pada nilai level sigma diketahui bahwa rata-rata nilai level sigma sebelum perbaikan yaitu 2,84 sedangkan setelah perbaikan yaitu sebesar 2,95. Hal tersebut menunjukkan adanya peningkatan level sigma sebesar 0,11 , sehingga terjadi peningkatan kualitas pada produk brownies kukus cokelat. 
188 | Salsabila Aulia Nurfaidah

\section{Acknowledge}

Peneliti mengucapkan terima kasih kepada Ibu Dr. Nita P. A. Hidayat, Ir., M.T selaku dosen pembimbing yang telah menyediakan waktu, tenaga, dan pikiran untuk memberikan ilmu serta arahan selama proses bimbingan penelitian. Peneliti juga mengucapkan terima kasih kepada pihak perusahaan CV. X yang telah mengizinkan penelitian ini dilakukan dan memberikan banyak informasi untuk kebutuhan penelitian.

\section{Daftar Pustaka}

[1] Womack, J. P., dan Jones, D. T., 2003. Lean thinking: Banish waste and create wealth in your corporation. Edisi 2. New York: Free Press

[2] Voehl, F., Harrington, H. J., Mignosa, C., dan Charron, R., 2013. The lean six sigma black belt handbook: Tools and methods for process acceleration. New York: A Productivity Press.

[3] Gaspersz, V., 2006. Lean six sigma for manufacturing and service industries. Jakarta: Gramedia Pustaka Utama.

[4] Gaspersz, V., dan Fontana, A., 2018. Lean Six Sigma for Manufacturing and Services Industries. Bogor: Vinchristo Publication. 